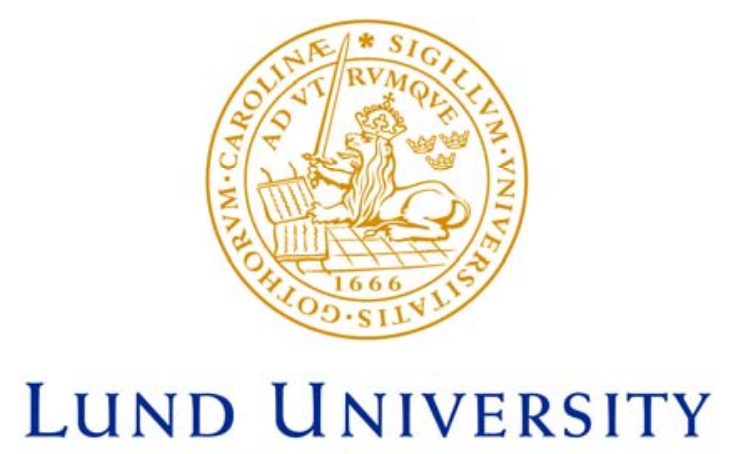

Faculty of Medicine

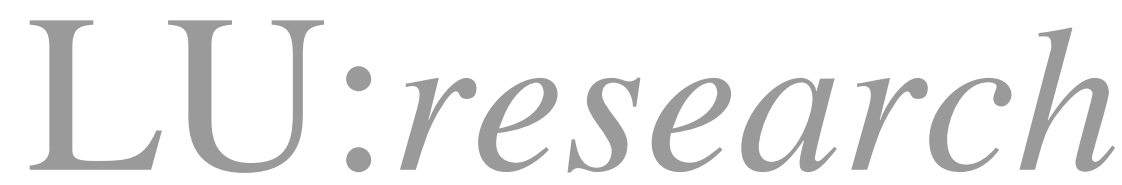

Institutional Repository of Lund University

This is an author produced version of a paper published in Contact Dermatitis. This paper has been peer-reviewed but does not include the final publisher proof-corrections or journal pagination.

Citation for the published paper:

Bruze, Magnus and Frick-Engfeldt, Malin and Gruvberger,

Birgitta and Isaksson, Marléne.

"Variation in the amount of petrolatum preparation applied at patch testing"

Contact Dermatitis, 2007, Vol: 56, Issue: 1, pp. 38-42.

http://dx.doi.org/10.1111/j.1600-0536.2007.00985.x

Access to the published version may

require journal subscription.

Published with permission from: Blackwell 


\section{Variation in the amount of petrolatum preparation applied at patch testing}

Bruze M, Frick-Engfeldt M, Gruvberger B, Isaksson M

Dept. of Occupational and Environmental Dermatology, Lund University, Malmö University Hospital, Malmö, Sweden

Corresponding author: Magnus Bruze, M.D., PhD

Department of Occupational and Environmental Dermatology

Malmö University Hospital,

SE 205-02 Malmö, Sweden

Phone: +46 40331760

Fax: $\quad+4640336213$

e-mail: magnus.bruze@med.lu.se 


\section{Abstract}

The elicitation of a positive patch test reaction in a given individual depends upon the dose of the sensitizer applied, the patch test technique, and the occlusion time. The dose is determined by the concentration and volume/amount of test preparation applied. If the same amount/volume of a test preparation is applied all the time with the same test technique (same area of skin) and occlusion time, it is appropriate to use concentration as a dose parameter. Most contact sensitizers are incorporated in petrolatum. With petrolatum as vehicle, it is impossible to repeatedly apply an exact volume/amount. This study was performed to investigate the inter- and intraindividual variation of petrolatum preparation applied at patch testing by 3 technicians. Weighing demonstrated that the 3 technicians had about the same precision in their petrolatum application. The investigation demonstrates that there is both an interindividual (statistically significant ) and intraindividual variation in the amounts of petrolatum applied at patch testing for the 3 technicians. Presently, there is no recommendation on what amount of petrolatum preparation to apply, which merits a decision to be taken based on thorough investigations on the appropriate volumes of petrolatum preparation to be applied in various patch test systems.

Keywords: Allergic contact dermatitis; contact allergy; dose/area; Finn Chamber ${ }^{\circledR}$; interindividual; intra-individual; standard series, weighing. 
The elicitation of a positive patch test reaction in a given individual depends upon: (i) the dose, i.e., the number of molecules of the sensitizer applied; (ii) the patch test technique, i.e, the vehicle used and type of occlusion; and (iii) the occlusion time (1-5). The dose is determined by the concentration and volume/amount of test preparation applied. Thus, if the same amount/volume of a test preparation is applied all the time with the same test technique (same area of skin) and occlusion time, it is appropriate to use concentration as a dose parameter. For most sensitizers, petrolatum is an appropriate vehicle as it is stable and seems to prevent/diminish degradation of the incorporated allergen as well as oxidation and polymerization (6-8). However, with petrolatum as the vehicle, it is impossible to repeatedly apply an exact volume/amount. An experienced and trained person can, however, keep the variation within a limited range $(9,10)$. Previous measurements at our department have demonstrated that this statement was true. However, the fact that some years had passed since these measurements were made and that new technicians had been employed the last few years led us to investigate whether there was an inter- and intraindividual variation of petrolatum preparation applied at patch testing.

\section{Materials and methods}

\section{Patch testing}

For patch testing with the standard patch test series, the Finn Chamber ${ }^{\circledR}$ (Epitest Ltd Oy, Tuusula, Finland) technique is used implying small chambers with a diameter of 8 millimetres. The patch test preparations included the standard series of the Swedish Contact Dermatitis Group as well as additional sensitizers tested at our department. These additional sensitizers are prepared at our department, mainly in petrolatum while the standard series is purchased from Chemotechnique Diagnostics, Tygelsjö, Sweden (Table 1). The petrolatum preparations made at our department are put in the same $5 \mathrm{ml}$ plastic syringes used for the petrolatum preparations from Chemotechnique Diagnostics. The application way of petrolatum preparation to the chambers varies but application as a string across the chamber predominates.

\section{Study design}

At our department 5 technicians and one nurse are participating in the patch testing procedure. One day when ordinary patch testing was carried out by 3 of them, all test strips mounted with 
Finn Chambers ${ }^{\circledR}$, to which our standard series with 49 petrolatum preparations had just been applied, were removed from each test cubicle and refrigerated until analysed. This procedure was carried out for all 3 technicians and involved the patches intended for 3 different patients. The technicians were not informed in advance about the study. Furthermore, the technicians did not communicate with each other until the removal process was completed.

\section{Weighing}

The petrolatum preparations were applied on Finn Chambers ${ }^{\circledR}$ attached to Scanpor ${ }^{\circledR}$ tape (Norgesplaster A/S, Vennesla, Norway). To be able to weigh only the aluminium chamber with petrolatum preparation, the chamber was gently removed from the tape with a pincette and the remaining adhesive on the chamber was wiped off with a cotton swab soaked in acetone. Thereafter, the individual aluminium chambers were weighed.

To calculate the weight of an unloaded aluminium chamber, 12 unloaded Finn Chambers ${ }^{\circledR}$ attached to Scanpor ${ }^{\circledR}$ tape were handled in the same way as the ones to which petrolatum preparations had been applied.

The weight of the petrolatum preparation in an individual Finn Chamber ${ }^{\circledR}$ was obtained by subtracting the weight of a loaded Finn Chamber ${ }^{\circledR}$ with the average weight of the unloaded chambers.

\section{Statistical calculation}

All statistical analyses were carried out using SPSS version 12.0 (SPSS Inc., Chicago, USA). The interindividual variation between the 3 technicians was analyzed using One-way Anova since the data for each individual were fairly symmetric with median values close to the means (Table 1, Fig. 1) and since the number of observations for each individual was large. The intraindividual variations were assessed using descriptive data such as mean, median, standard deviation and coefficient of variation (C.V.) as well as Levene's test for homogeneity of variance.

\section{Results}

The individual weights of the 12 unloaded aluminium chambers were recorded and the calculated mean was $54.2 \mathrm{mg}$ (95\% CI 54.0-54.4). 
The weights of the 49 petrolatum preparations are given in Table 1 for the 3 technicians.

The 3 technicians had about the same precision in their petrolatum application, i. e. they hade about the same C.V. and standard deviation. This conclusion was supported by Levene's test, which could not find significant differences in the variance $(\mathrm{p}=0.088)$. One-way ANOVA analysis showed that there was a significant $(\mathrm{p}<0.001)$ interindividual variation between the three technicians. Paired comparisons between the technician (i. e. technician 1 with technician 2; technician 1 with technician 3; technician 2 with technician 3 etc.) also showed significant differences $(\mathrm{p}<0.001)$.

\section{Discussion}

With regard to contact allergy, the dose of a sensitizer per unit skin area is decisive for both sensitization and elicitation (1-5). Therefore, vehicles which enable an accurate measurement of the dose of a sensitizer applied at patch testing must be used when knowledge of the dose per unit skin area is of utmost importance, for example elicitation threshold studies in humans and animals. Knowledge of the doses used is also necessary, provided that the same patch test technique has been used, when comparing patch test data between various patch test centres and when performing multicentre studies including patch testing.

Petrolatum is the most commonly used vehicle for contact sensitizers in the standard series and additional series. Major reasons for this is that petrolatum as vehicle is practical and economical. It is easy to use and it prevents/diminishes degradation/oxidation/polymerization of sensitizers (6-8). However, with petrolatum as vehicle it is virtually impossible to apply an exact dose at patch testing. Even then, this does not disqualify petrolatum as vehicle for screening purposes of contact allergy, neither for comparisons of patch test data between departments. With petrolatum as vehicle, comparisons and multicentre studies including patch testing can be performed provided that "equivalent" doses have been used and that 2 factors are known, i.e. (i) the average dose applied at one department and (ii) the standard deviation (4).

When using the weight of various petrolatum preparations containing contact sensitizers as a parameter for the volume/weight of petrolatum applied, the density of the contact sensitizer 
will affect the result. However, in this study the influence of the densities of the contact sensitizers on the weight of petrolatum preparations was considered minute and therefore ignored, as the densities of most contact sensitizers in the present investigation are close to the density of petrolatum and/or the concentrations of the contact sensitizers present in the petrolatum preparations were low. Expectedly, the results of this study demonstrate that our technicians can keep the variation of petrolatum application within a limited range. Still, for the individual technician this means that there is a factor of approximately 2 (1.9, 2.2 and 2.4, respectively) for the difference between the highest and lowest doses applied. However, although the 3 technicians have the same precision in their weighing, they have different perceptions about the correct amount to weigh since their mean differs a lot.

Surprisingly, there was a big difference in average petrolatum applications between the 3 technicians. For example, as seen in table 1, the amount between the technicians varies with a factor 2-3 for 14/48 allergens. These findings indicate that the new technicians have been taught the need of a "standardized" amount of petrolatum preparation applied at patch testing but not on what amount to apply. Currently, there is no recommendation for petrolatum while a liquid is recommended to be applied in a volume of $15 \mu \mathrm{l}$ with the Finn Chamber $^{\circledR}$ technique (11).

The demonstrated intra- and inter-individual differences in petrolatum applications may have clinical implications. The significance of dose has been investigated in a previous study in a small number of nickel-hypersensitive persons (12). They were patch tested with nickel sulphate at the same concentration but with various doses; $2.5 \mathrm{mg}, 5 \mathrm{mg}, 10 \mathrm{mg}$ and $15 \mathrm{mg}$. All doses yielded positive responses but as no information was given on the coverage of the test area, actually no conclusions on the clinical significance of dose can be drawn. For a positive reaction the minimal criteria is on infiltrated erythema covering the whole test area (4). The preservative methyldibromo glutaronitrile (MDBGN) can be used as an example of a possible clinical implication. During the past years, the optimal patch test concentration of MDBGN has been extensively discussed. However, in none of the MDBGN studies reviewed in the article by Bruze et al (13) the amount of petrolatum used for the patch testing was given. One major reason for this is that there have not been any amounts of petrolatum preparations recommended of universal acceptance for the various patch test techniques used. 
From Table 2 it is obvious that also the amount of petrolatum preparation applied is important for the dose. Actually, comparing the doses applied by technician no. 1 for the MDBGN preparations at $1.0 \%$ and $0.5 \%$ with the corresponding doses for technician no. 2 , the former are lower and equivalent to the doses applied by technician no. 2 for the MDBGN preparations at $0.5 \%$ and $0.3 \%$, respectively, provided that the petrolatum preparation is not spread outside the test area.

To the best of our knowledge, this is the first time the amounts of petrolatum preparations have been investigated when routinely patch testing dermatitis patients without the technicians/patch test preparation applicators having been informed on what was planned. In a British study a nurse, being aware of the purpose of the study, prepared 25 separate Finn Chambers ${ }^{\circledR}$ with petrolatum preparations, where the average petrolatum weight was $11 \mathrm{mg}$, and where there was no significant weight variation (10). In a Belgian study on the amounts of petrolatum preparation applied to test chambers by 7 dermatologists on 4 consecutive days, significant weight variation occurred interindividually and also intraindividually from day to day, although they were aware of the study (14).

In summary, this investigation demonstrates that there is both an intraindividual and interindividual variation in the amounts of petrolatum applied at patch testing for the 3 technicians. The individual technician can keep the variation within a limited range while the interindividual variation necessitates steps to be taken; i.e. the amount of petrolatum preparation to be applied has to be decided, preferably by the European Society of Contact Dermatitis. Such a decision has to be based on thorough investigations on the appropriate volumes of petrolatum preparation to be applied in various patch test systems. When an appropriate volume has been decided for a particular patch-test system, technicians can be trained to weigh this amount. Thereby, “equivalent” doses are achieved which makes comparisons and multicentre studies possible provided that the average dose applied at one department as well as the standard deviation are stated (4). 


\section{References}

1. Upadhye MR, Maibach HI. Influence of area of application of allergen on sensitization in contact dermatitis. Contact Dermatitis 1992: 27:281-286.

2. Bruze M. Patch testing with nickel sulphate under occlusion for five hours. Acta Derm Venereol 1988: 68:361-364.

3. Friedmann PS, Moss C, Shuster S, Simpson JM. Quantitative relationships between sensitizing dose of DNCB and reactivity in normal subjects. Clin Exp Immunol 1983: 53:709-715.

4. Bruze M, Conde-Salazar L, Goossens A, Kanerva L, White IR. Thoughts on sensitizers in a standard patch test series. The European Society of Contact Dermatitis. Contact Dermatitis 1999: 41:241-250.

5. Webster RC, Maibach HI: Percutaneous absorption relative to occupational dermatology. In: Occupational and industrial dermatology, Maibach H (ed): Chicago: Yearbook Medical Publishers Inc., 1987, 241-257.

6. Bruze M, Fregert S. Studies on purity and stability of photopatch test substances. Contact Dermatitis 1983: 9:33-39.

7. Isaksson M, Gruvberger B, Persson L, Bruze M. Stability of corticosteroid patch test preparations. Contact Dermatitis 2000: 42:144-148.

8. Andersen KE, Rastogi SC, Carlsen L. The Allergen Bank: a source of extra contact allergens for the dermatologist in practice. Acta Derm Venereol 1996: 76:136-140.

9. $\quad$ Fischer T, Maibach HI. Finn chamber patch test technique. Contact Dermatitis 1984: 11:137-140.

10. Moffitt DL, Sharp LA, Sansom JE. Audit of Finn Chamber patch test preparation. Contact Dermatitis 2002: 47:334-336.

11. Bjorkner B, Bruze M, Moller H. High frequency of contact allergy to gold sodium thiosulfate. An indication of gold allergy? Contact Dermatitis 1994: 30:144-151.

12. Memon AA, Friedmann PS. Studies on the reproducibility of allergic contact dermatitis. British Journal of Dermatology 1996: 134:208-214

13. Bruze M, Goossens A, Gruvberger B. Recommendation to include methyldibromo glutaronitrile in the European standard patch test series. Contact Dermatitis 2005: 52:24-28.

14. Antoine JL, Lachapelle JM. Variations in the quantities of petrolatum applied in patch testing. Derm Beruf Umwelt 1988: 36:191-194. 


\section{Legends}

Figure 1. Histograms showing the distribution of weights in mg of petrolatum preparations applied at patch testing for 3 technicians, individually. 

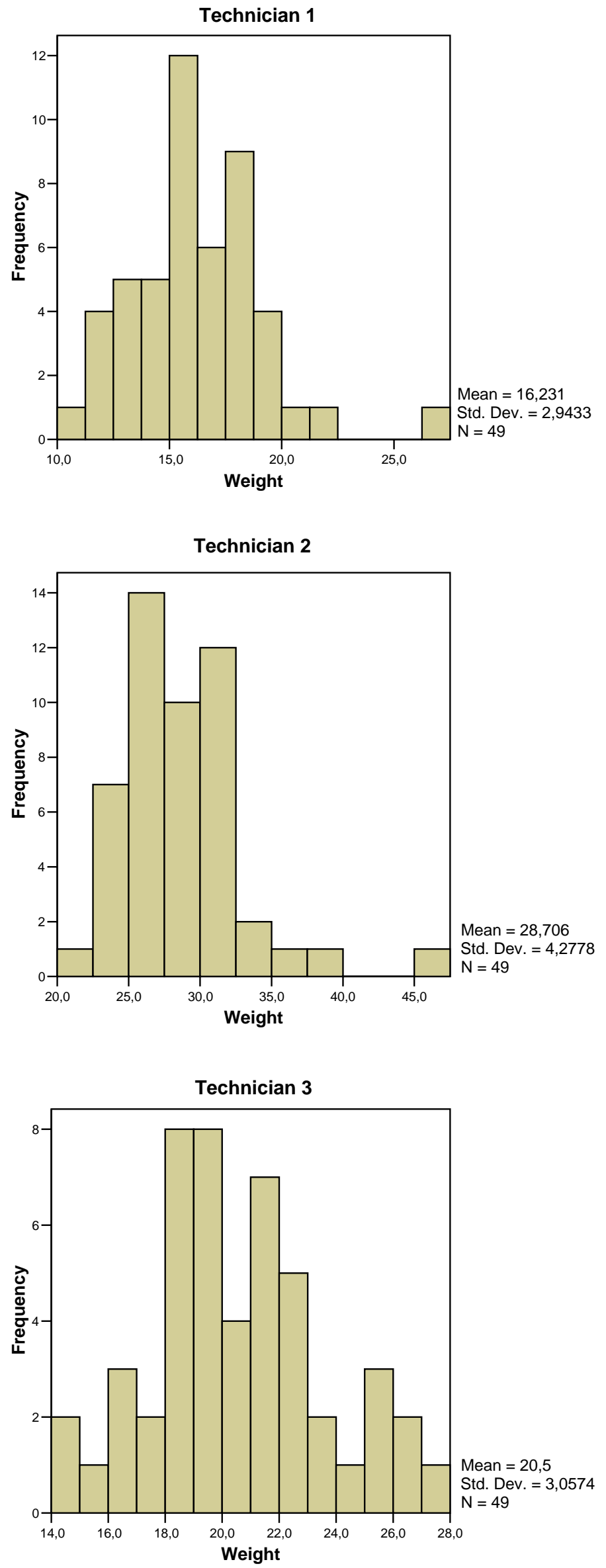
Table 1. The standard series used at the Department of Occupational and Environmental Dermatology at the time of the study as well as the weighed amount of petrolatum preparations for each lab technician.

\begin{tabular}{|c|c|c|c|c|}
\hline \multirow[t]{2}{*}{ Preparation } & \multirow{2}{*}{$\begin{array}{l}\text { Conc.\% } \\
\text { w/w }\end{array}$} & \multicolumn{3}{|c|}{ Weight (g)* } \\
\hline & & Technician 1 & Technician 2 & Technician 3 \\
\hline Potassium dichromate & 0.5 & 14.3 & 25.8 & 26.6 \\
\hline 4-phenylenediamine dihydrochloride & 0.94 & 17.7 & 27.8 & 22.3 \\
\hline Thiuram mix & 1.0 & 18.1 & 32.6 & 18.0 \\
\hline Neomycin sulfate & 20.0 & 19.9 & 29.1 & 21.6 \\
\hline Cobalt chloride hexahydrate & 0.5 & 15.7 & 23.6 & 21.9 \\
\hline Benzocaine & 5.0 & 15.6 & 32.2 & 19.2 \\
\hline Nickel sulfate hexahydrat & 5.0 & 17.9 & 30.8 & 22.4 \\
\hline Quinoline mix & 6.0 & 15.7 & 31.5 & 18.9 \\
\hline Colophony & 20.0 & 11.1 & 31.7 & 18.7 \\
\hline Paraben mix & 15.0 & 19.5 & 33.4 & 19.1 \\
\hline Black rubber mix & 0.6 & 12.7 & 25.8 & 14.4 \\
\hline Sesuiterpene lactone mix & 0.1 & 12.8 & 29.4 & 18.0 \\
\hline Mercapto mix & 2.0 & 17.6 & 26.3 & 19.8 \\
\hline Epoxy resin & 1.0 & 20.9 & 30.5 & 18.1 \\
\hline Balsam peru & 25.0 & 22.0 & 38.0 & 18.5 \\
\hline 4-tert-butylphenol formaldehyde resin & 1.0 & 14.7 & 29.6 & 15.6 \\
\hline Primin & 0.01 & 14.0 & 29.1 & 14.6 \\
\hline Fragrance mix & 8.0 & 12.4 & 30.6 & 16.8 \\
\hline Ethylenediamine dihydrochloride & 1.0 & 16.7 & 29.0 & 19.9 \\
\hline Lyral & 5.0 & 19.8 & 28.3 & 25.6 \\
\hline Caine mix II & 10.0 & 13.3 & 24.5 & 19.7 \\
\hline Lichen acid mix & 0.3 & 13.5 & 26.4 & 22.2 \\
\hline Tixocortol-21-pivalate & 0.1 & 12.1 & 31.9 & 23.0 \\
\hline Toluensulfonamid formaldehyd resin & 10.0 & 18.4 & 31.1 & 20.3 \\
\hline Budesonide & 0.01 & 14.7 & 26.0 & 21.2 \\
\hline Methyldibromoglutaronitrile & 0.3 & 15.6 & 31.7 & 23.6 \\
\hline Qakmoss absolute & 2.0 & 15.9 & 36.9 & 16.8 \\
\hline Gold sodium thiosulfate & 2.0 & 12.2 & 26.1 & 21.9 \\
\hline Mercaptobenzothiazole & 2.0 & 15.2 & 25.5 & 16.9 \\
\hline Quaternium 15 & 1.0 & 11.3 & 29.3 & 18.2 \\
\hline Thimerosal & 0.1 & 18.3 & 27.2 & 19.5 \\
\hline Palladium chloride & 2.0 & 13.1 & 29.7 & 19.5 \\
\hline Phenol formaldehyde resin & 1.0 & 15.5 & 26.7 & 18.1 \\
\hline Bisphenol F resin (Novolac) DEN 431 & 0.25 & 15.9 & 25.3 & 17.6 \\
\hline Methyldibromoglutaronitrile & 0.5 & 18.0 & 30.5 & 21.1 \\
\hline Methyldibromoglutaronitrile & 1.0 & 15.3 & 24.1 & 17.5 \\
\hline Textile colours mix & 3.2 & 16.8 & 30.3 & 26.1 \\
\hline Phenylglycidyl ether & 0.25 & 27.0 & 22.5 & 20.3 \\
\hline Diphenylmethan-4,4'-diisocyanat & 2.0 & 17.8 & 24.8 & 21.4 \\
\hline 4,4'-Diaminodiphenylmethane & 0.25 & 17.2 & 21.0 & 22.2 \\
\hline Epoxy resin, cycloaliphatic & 0.5 & 17.9 & 27.1 & 22.0 \\
\hline Disperse Blue 106 & 0.1 & 16.1 & 26.8 & 26.3 \\
\hline Disperse Blue 124 & 0.1 & 15.2 & 24.3 & 25.7 \\
\hline Disperse Blue 35 & 0.5 & 17.0 & 28.4 & 24.3 \\
\hline Disperse Yellow 3 & 0.5 & 19.0 & 25.6 & 25.9 \\
\hline Disperse Orange 1 & 0.5 & 16.8 & 45.8 & 20.9 \\
\hline Disperse Orange 3 & 0.5 & 14.6 & 24.3 & 19.2 \\
\hline Disperse Red 1 & 0.5 & 15.9 & 25.9 & 27.3 \\
\hline
\end{tabular}


Mean

95\% Confidential interval for mean

Median

Standard deviation

Coefficient of variation (\%)
16.2

15.4-17.1

28.7

15.9

2.94

18.1
28.7

28.4

4.28

14.9
20.5

19.6-21.4

20.3

3.06

14.9 
Table 2. The variation in dose per area for the 3 different concentrations of methyldibromoglutaronitrile when weighed by the 3 technicians.

\begin{tabular}{lcccc}
\hline Preparation & Conc & \multicolumn{3}{c}{ Dose/area $\left(\mathrm{mg} / \mathrm{mm}^{2}\right)^{*}$} \\
\cline { 3 - 5 } & $(\%) \mathrm{w} / \mathrm{w}$ & Technician 1 & Technician 2 & Technician 3 \\
\hline Methyldibromoglutaronitrile & 0.3 & 0.94 & 1.90 & 1.42 \\
Methyldibromoglutaronitrile & 0.5 & 1.80 & 3.05 & 2.11 \\
Methyldibromoglutaronitrile & 1.0 & 3.06 & 4.82 & 3.50 \\
\hline
\end{tabular}

* Area of the Finn Chambers ${ }^{\circledR} 50 \mathrm{~mm}^{2}$ 